\title{
A Potentiostat Readout Circuit with a Low-Noise and Mismatch-Tolerant Current Mirror Using Chopper Stabilization and Dynamic Element Matching for Electrochemical Sensors
}

\author{
Kyeongsik Nam, Gyuri Choi, Hyungseup Kim (D, Mookyoung Yoo and Hyoungho Ko *(D)
}

Citation: Nam, K.; Choi, G.; Kim, H.; Yoo, M.; Ko, H. A Potentiostat Readout Circuit with a Low-Noise and Mismatch-Tolerant Current Mirror Using Chopper Stabilization and Dynamic Element Matching for Electrochemical Sensors. Appl. Sci. 2021, 11, 8287. https://doi.org/ 10.3390/app11188287

Academic Editors: Wen-Hsiang

Hsieh, Jia-Shing Sheu and

Minvydas Ragulskis

Received: 21 July 2021

Accepted: 3 September 2021

Published: 7 September 2021

Publisher's Note: MDPI stays neutral with regard to jurisdictional claims in published maps and institutional affiliations.

Copyright: (c) 2021 by the authors. Licensee MDPI, Basel, Switzerland. This article is an open access article distributed under the terms and conditions of the Creative Commons Attribution (CC BY) license (https:// creativecommons.org/licenses/by/ $4.0 /)$.
Department of Electronics Engineering, Chungnam National University, Daejeon 34134, Korea; ksnam@o.cnu.ac.kr (K.N.); cyeakl@o.cnu.ac.kr (G.C.); hyungseup@cnu.ac.kr (H.K.); anruddl2@gmail.com (M.Y.) * Correspondence: hhko@cnu.ac.kr

\begin{abstract}
This paper presents a potentiostat readout circuit with low-noise and mismatch-tolerant current mirror using chopper stabilization and dynamic element matching (DEM) for electrochemical sensors. Current-mode electrochemical sensors are widely used to detect the blood glucose and viruse in the diagnosis of various diseases such as diabetes, hyperlipidemia, and the H5N1 avian influenza virus (AIV). Low-noise and mismatch-tolerant characteristics are essential for sensing applications that require high reliability and high sensitivity. To achieve these characteristics, a proposed potentiostat readout circuit is implemented using the chopper stabilization scheme and the DEM technique. The proposed potentiostat readout circuit consists of a chopper-stabilized programmable gain transimpedance amplifier (TIA), gain-boosted cascode current mirror, and a control amplifier (CA). The chopper scheme, which is implemented in the TIA and CA, can reduce low frequency noise components, such as $1 /$ f noise, and can obtain low-noise levels. The mismatch offsets of the cascode current mirror can be reduced by the DEM operation. The proposed currentmirror-based potentiostat readout circuit is designed using a standard $0.18 \mu \mathrm{m}$ CMOS process and can measure the sensor current from $350 \mathrm{nA}$ to $2.8 \mu \mathrm{A}$. The input-referred noise integrated from $0.1 \mathrm{~Hz}$ to $1 \mathrm{kHz}$ is $21.7 \mathrm{pA}_{\mathrm{RMS}}$, and the power consumption was $287.9 \mu \mathrm{W}$ with a $1.8 \mathrm{~V}$ power supply.
\end{abstract}

Keywords: low-noise; mismatch-tolerant; electrochemical sensor; current mirror; chopper stabilization; dynamic element matching (DEM)

\section{Introduction}

Current-mode electrochemical sensors have been widely used to detect the blood glucose and viruses in the diagnosis of various diseases such as diabetes, hyperlipidemia, and the H5N1 avian influenza virus (AIV) [1-3]. The early diagnosis of highly pathogenic viruses such as H5N1 AIV is significant for preventing their rapid spread. A currentmode sensing technique using an aptamer-based field-effect transistor with an extended gate was previously introduced to detect AIV [3]. In addition, blood glucose sensing based on the electrochemical current-mode sensors with a potentiostat biasing circuit was reported in $[1,2]$.

A general sensing mechanism with a three-electrode potentiostat electrochemical current-mode sensor is shown in Figure 1a [4]. For electrochemical current-mode sensors for blood glucose sensing, the level of diabetes can be detected by sensing the current generated through various potential differences according to the change in the concentration of glucose [4,5].

Glucose or virus concentrations are generally measured using an amperometric electrochemical sensor. A three-electrode structure with a potentiostat consisting of a working electrode (WE), reference electrode (RE), and counter electrode (CE) can measure the current generated by the electrochemical reaction [6,7]. When we assume a very small voltage drop across the current meter, the voltage difference between the WE and RE can be kept 
constant by the feedback error amplifier [8]. The current generated by the electrochemical reaction flows from the $\mathrm{CE}$ to the $\mathrm{WE}$, and this current is measured by the current meter. Therefore, the potentiostat sensor converts the solution concentration into a current. This characteristic of the sensor is suitable for bio-sensing applications such as blood glucose and virus analyses [9-11].

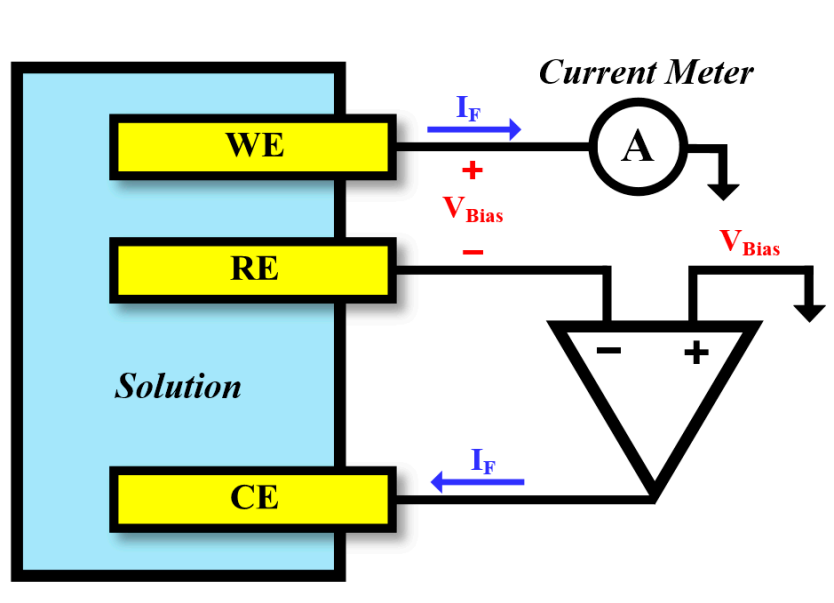

(a)

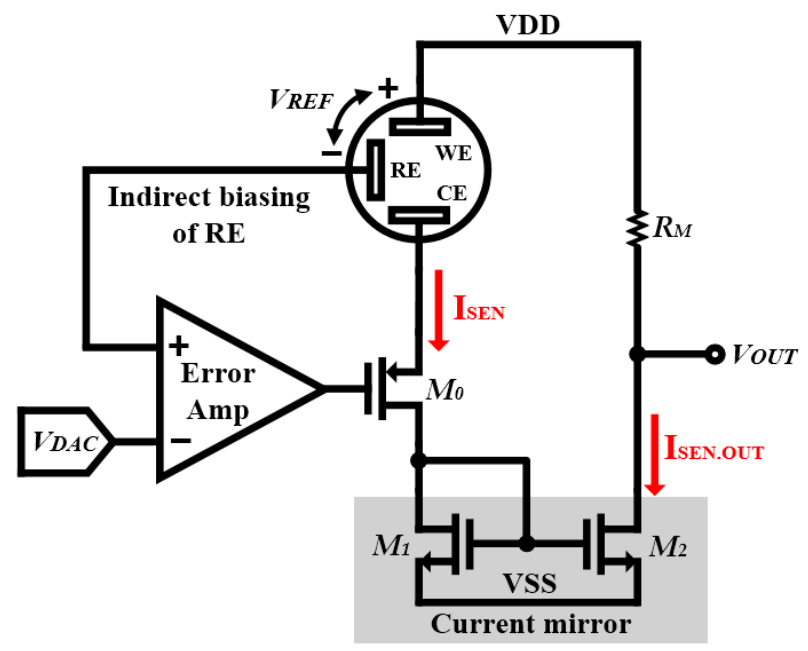

(b)

Figure 1. (a) Three-electrode potentiostat electrochemical sensor; (b) Conventional structure of the current mirror based potentiostat readout circuit.

The conventional circuit of the current mirror based potentiostat readout circuit is shown in Figure $1 \mathrm{~b}$. The $M_{0}$ and the control amplifier (CA) generate a feedback loop, and the $V_{R E F}$ between $\mathrm{WE}$ and RE, which is $V_{D D}-V_{D A C}$, is stabilized. The current from the electrochemical sensor, $I_{S E N}$, is copied by the current mirror, $M_{1}$ and $M_{2}$. In this architecture, however, the mismatch between the current mirror transistors due to the process variations and channel-length modulation deteriorates the sensing accuracy. Moreover, the $1 / \mathrm{f}$ noise components generated in $M_{1}$ and $M_{2}$ act as the main noise contributors. Therefore, designing a current mirror with low-noise $[12,13]$ and mismatch-tolerant characteristics is critical $[14,15]$.

In this study, a potentiostat sensing circuit with a low-noise and mismatch-tolerant current mirror is proposed. The chopper stabilization scheme and dynamic element matching (DEM) technique are integrated to reduce the low-frequency noise and mismatch in the current mirror. The gain-boosted cascode scheme is also applied to the current mirror to reduce the mismatch between the drain-source voltages $\left(V_{D S}\right)$ of the current mirror. The mirrored electrochemical current is converted to the output voltage by a low-noise chopper-stabilized transimpedance amplifier (TIA).

In previous studies [16,17], a different chopper frequency and DEM frequency are used, and this may introduce performance degradation due to the intermodulation distortion (IMD) between the chopper and DEM frequencies [18]. The low DEM frequency also requires the lower cut-off frequency of LPF, which consumes a large circuit area.

Because the square waveform has odd-harmonics, if the DEM clock and the chopper clock are operated at different frequencies, the interaction between these harmonics can generate IMD, which can degrade the signal quality.

As a result, the proposed readout circuit used the same frequency for the chopper and the DEM, therefore minimizing the IMD between the chopper and DEM. Moreover, the relatively higher operating frequency of the chopper and the DEM can relax the area consumption of the LPF.

The remainder of the paper is organized as follows. Section 2 presents the circuit implementation of the proposed current-mirror-based potentiostat readout circuit. Section 3 
presents the simulation results of the proposed readout circuit. Finally, Section 4 concludes the paper with a performance summary and comparison.

\section{Proposed Current-Mirror-Based Potentiostat Readout Circuit}

A block diagram of the proposed potentiostat readout circuit is shown in Figure 2. The proposed circuit consists of potentiostat biasing, current mirror, and TIA stages. In the potentiostat biasing stage, the voltage potential between the WE and RE is maintained by the feedback loop. In the current mirror stage, the current from the $\mathrm{CE}$ is copied by the low-noise and mismatch-tolerant current mirror. In the TIA stage, the current from the current mirror stage is converted to a voltage signal. This voltage signal can be converted to a digital code using an analog-to-digital converter (ADC).

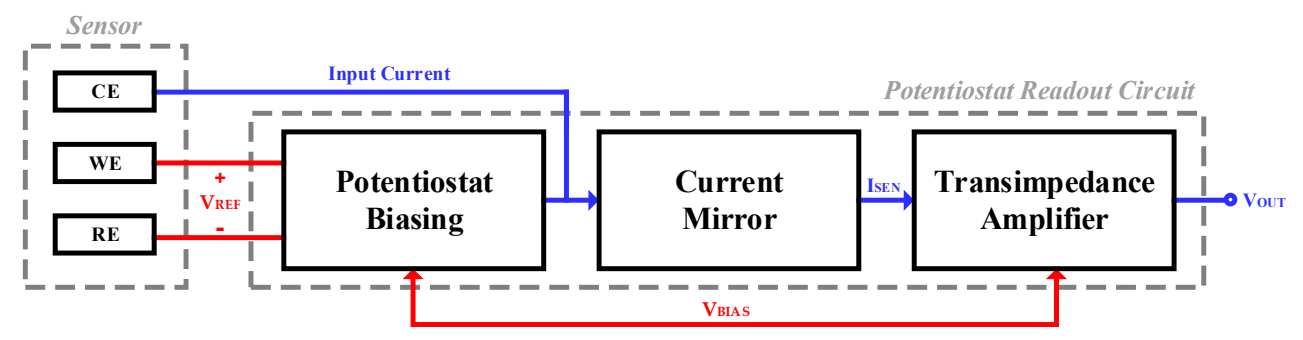

Figure 2. Block diagram of the proposed potentiostat readout circuit.

The top architecture of the proposed current-mirror-based potentiostat readout circuit is shown in Figure 3. The input stage of the readout circuit consists of a sensor and CA. The CA generates a feedback loop with an $M_{5}$. It maintains a constant $V_{R E F}$ between RE and WE. The $V_{R E F}$ is calculated as

$$
V_{R E F}=V_{W E}-V_{R E}=V_{D D}-V_{B 1}
$$

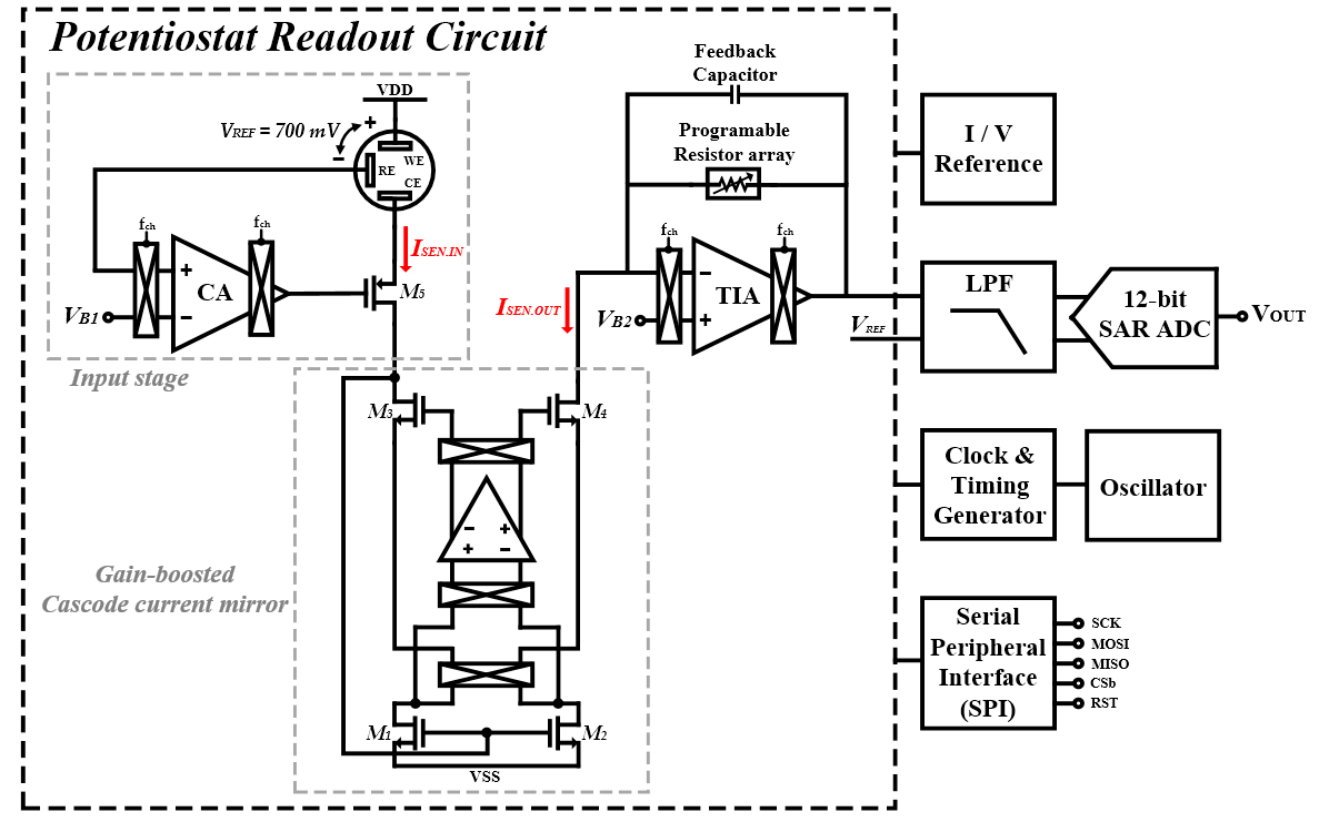

Figure 3. Top architecture of proposed current mirror based potentiostat readout circuit.

The current from the $\mathrm{CE}$ is mirrored by the gain-boosted cascode current mirror stage. The mirrored current is converted to the voltage through the TIA stage. Here, the transimpedance gain is programmable to adjust the gain. The low-pass filter (LPF) filters out the unwanted high-frequency components, and also acts as an antialiasing filter before a 12-bit successive approximation register (SAR) ADC. The internal operating parameters, 
including the clock timing, transimpedance gain, $V_{B 1}$ voltage, and chopper frequency are programmable, through a serial peripheral interface (SPI).

The architecture of the proposed current mirror is shown in Figure 4a. The current input, $I_{I N}$, is mirrored to the output current, $I_{O U T}$. To increase the output resistance of the current mirror and to reduce the number of errors due to the channel-length modulation, a gain-boosted cascode scheme is adopted. The $\mathrm{W} / \mathrm{L}$ ratio between $M_{a}$ and $M_{b}$ determines the current ratio between $I_{I N}$ and $I_{O U T}$. Thus, the mismatch derived from the process variation between $M_{a}$ and $M_{b}$ directly affects the accuracy of the current mirror. The $I_{I N}$ is converted to the gate voltage by the diode-connection between the drain of $M_{c}$ and the gate of $M_{a}$, and the gate voltage is converted to the $I_{O U T}$ by the transconductance of $M_{b}$; thus, the flicker noises from $M_{a}$ and $M_{b}$ largely contribute to the overall noise. In addition, the flicker noise from the gain-boosting amplifier acts as the main noise contributor. In this design, these mismatches and low-frequency noise components can be cancelled by the four-phase combinations of the chopper and DEM.

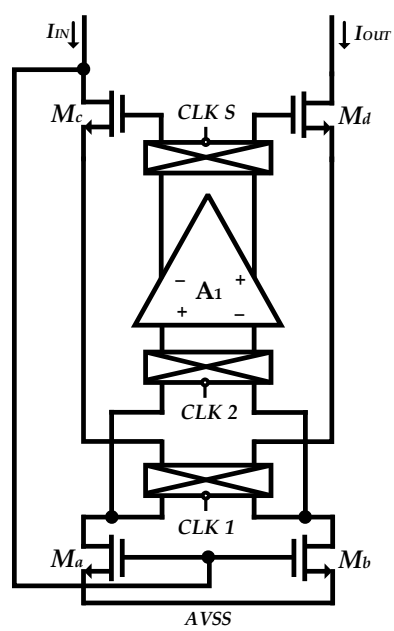

(a)
Timing diagram

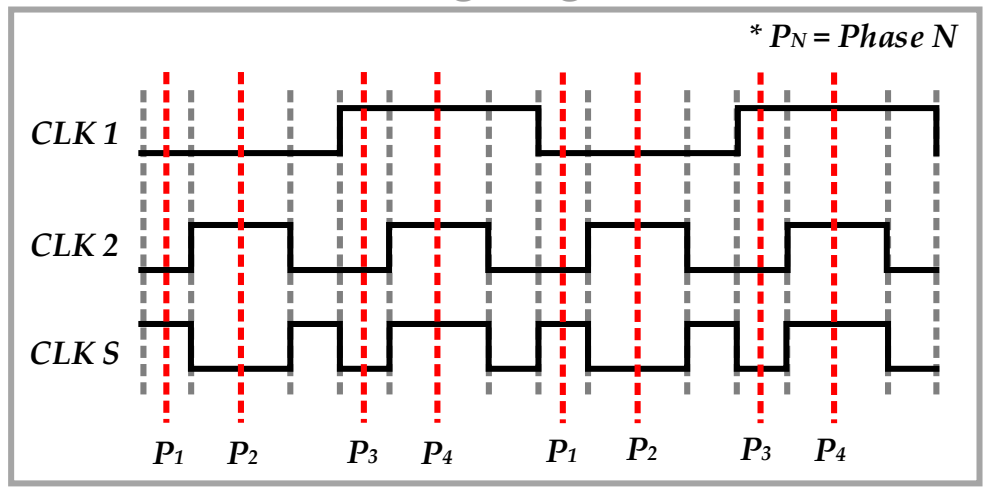

(b)

Figure 4. (a) Architecture of the proposed current mirror; (b) timing diagram of the chopper with current mirror using the DEM technique.

In Figure $4 b$, the current mirror is operated in four phases as a combination of three switching signals, CLK 1, CLK 2, and CLK S. The connections between the mirror transistors and amplifier are altered periodically as $P_{1}, P_{2}, P_{3}$, and $P_{4}$. The mismatches between the elements can be averaged out. In this current mirror, the chopper operation and dynamic element matching operation are merged into four phases. The low-frequency noise of the current mirror and amplifier are up-modulated by the chopper operation. The mismatch between the transistors in the current mirror and the amplifier is averaged, and thus a highly accurate current mirror operation with low noise is achieved.

The circuit configuration of the proposed current mirror as the phases of the combined chopper and DEM operations are illustrated in Figure 5. At the point of the connection around $M_{3}$, in Phase 1 , the source of $M_{3}$ is connected to the drain of $M_{2}$, and the gate of $M_{3}$ is connected to the negative output of the amplifier. In Phase 2, the source of $M_{3}$ remains connected to the drain of $M_{2}$; however, the gate of $M_{3}$ is connected to the positive output of the amplifier. In Phase 3, the source of $M_{3}$ is connected to the drain of $M_{1}$, and the gate of the $M_{3}$ is connected to the positive output of the amplifier. In Phase 4, the source of $M_{3}$ is connected to the drain of $M_{1}$, and the gate of $M_{3}$ is connected to the negative output of the amplifier. Using these four-phase combinations of the chopper and DEM techniques, the mismatches and the low-frequency noise components can be averaged out. 
Dynamic Element Matching (DEM) Configuration

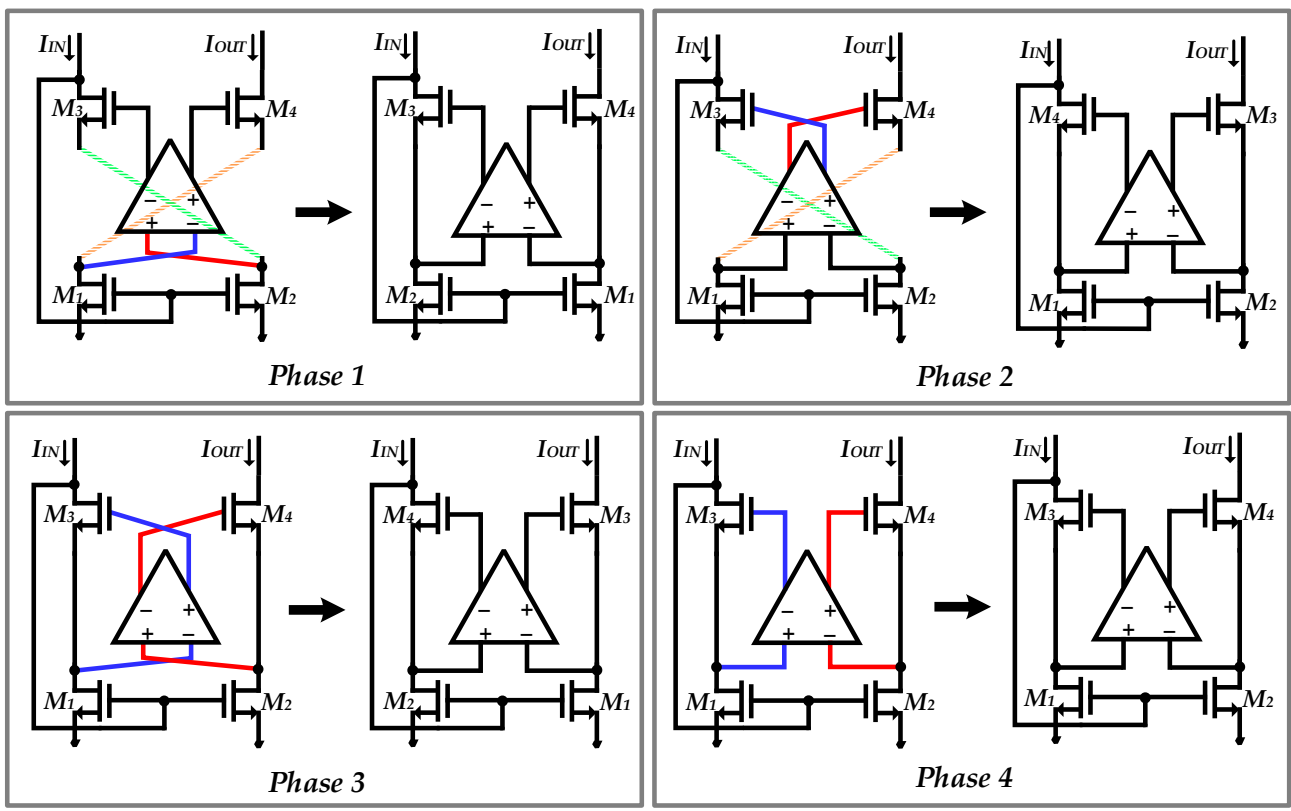

Figure 5. Operation principles of chopper and DEM technique.

Figure 6 shows the single-ended chopper operational amplifiers used in the implementation of the CA and the TIA. The amplifier adopts complementary input stages of the PMOS and NMOS differential pairs for the rail-to-rail input common-mode range. The intermediate stage is implemented using a folded-cascode topology with class-AB biasing, and the output stage is implemented in class-AB. The choppers in front of both the input stage and common-gate stages are implemented, as shown in Figure 6. The individual switch in the chopper is implemented using the CMOS transmission gate, and the chopping frequency of this circuit is $125 \mathrm{kHz}$ having non-overlapping clock. Non-overlapping clock have 10 ns duration.

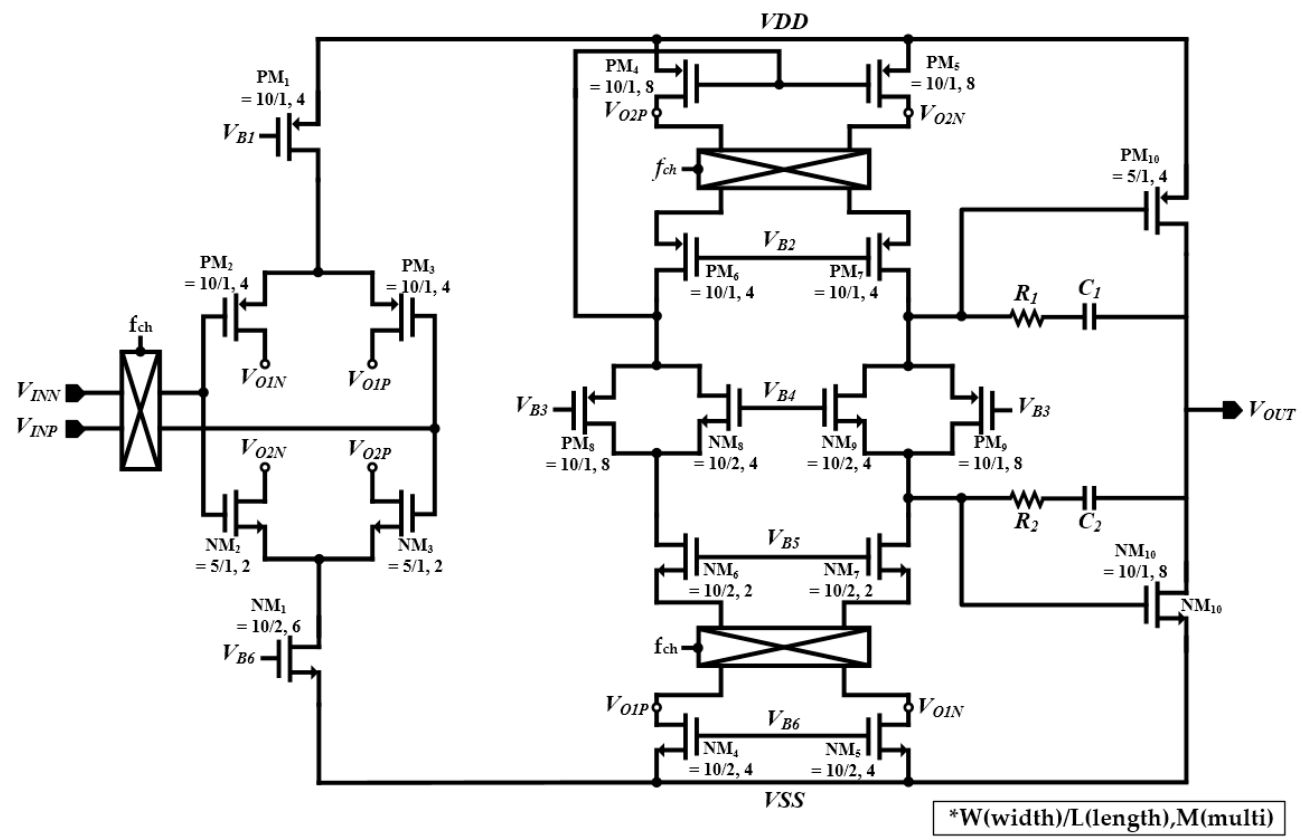

Figure 6. Schematic of the single-ended chopper amplifier. 
The chopper amplifier modulates the input signal to the high chopping frequency band to avoid the low-frequency flicker noise. The modulated signal is amplified and demodulated to the baseband using an output chopper. Here, the offset and the low-frequency noise are up-modulated by the output chopper, and is attenuated by the following LPF. Thus, a thermal-noise-limited signal-to-noise ratio (SNR) can be achieved using the chopper operation.

Figure 7 shows the fully differential amplifier used for gain boosting of the current mirror. A general two-stage folded-cascode Miller-compensated topology with common mode feedback (CMFB) is adopted. In this gain-boosted current mirror, because the input common mode level is low (approximately 100-200 mV), and the PMOS input stage is exploited, two source followers are added to the CMFB circuit to reduce the resistive loading for common mode detection.

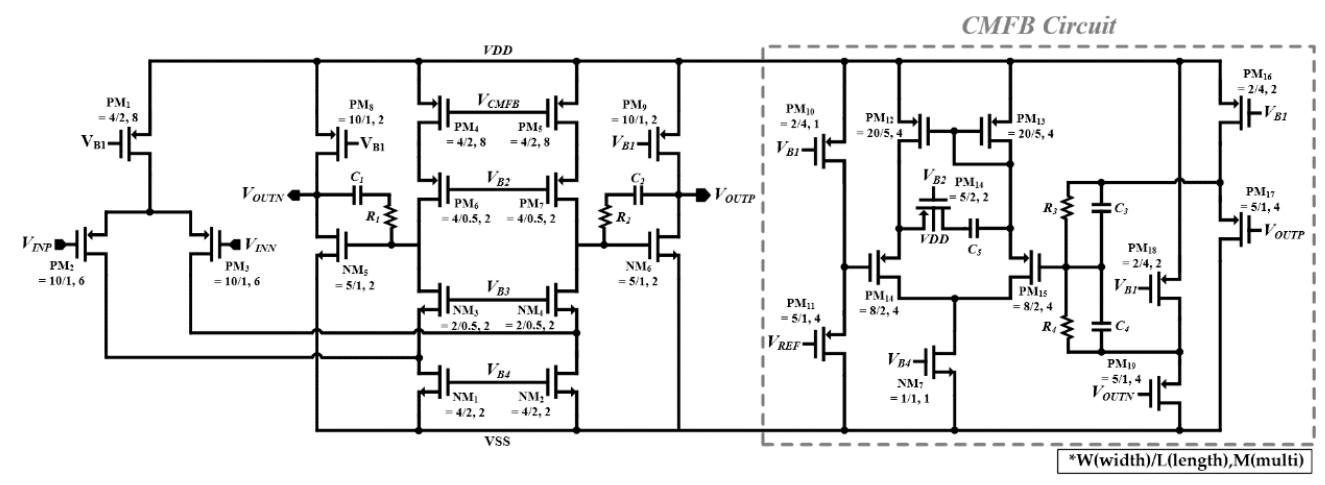

Figure 7. Schematic of the fully-differential amplifier.

\section{Results and Discussions}

A three-port electrochemical sensor was modeled using a voltage controlled resistor, as shown in Figure 8 [19-21]. The resistance between the RE and CE is modeled as a constant resistor at $10 \mathrm{k} \Omega$. The typical voltage difference between the $\mathrm{WE}$ and $\mathrm{RE}$ was set to be $700 \mathrm{mV}$. In this circuit, the WE was forced by the VDD supply $(1.8 \mathrm{~V})$. The RE is typically indirectly biased to $1.1 \mathrm{~V}$ by the virtual short between the feedback amplifier input nodes. The current change due to the electrochemical reaction is modeled using a voltage-controlled resistor, which varies from 250 to $2250 \mathrm{k} \Omega$, and is implemented using Verilog-A. Since the chip is under fabricate, post layout simulation was performed using parasitic extraction (PEX).

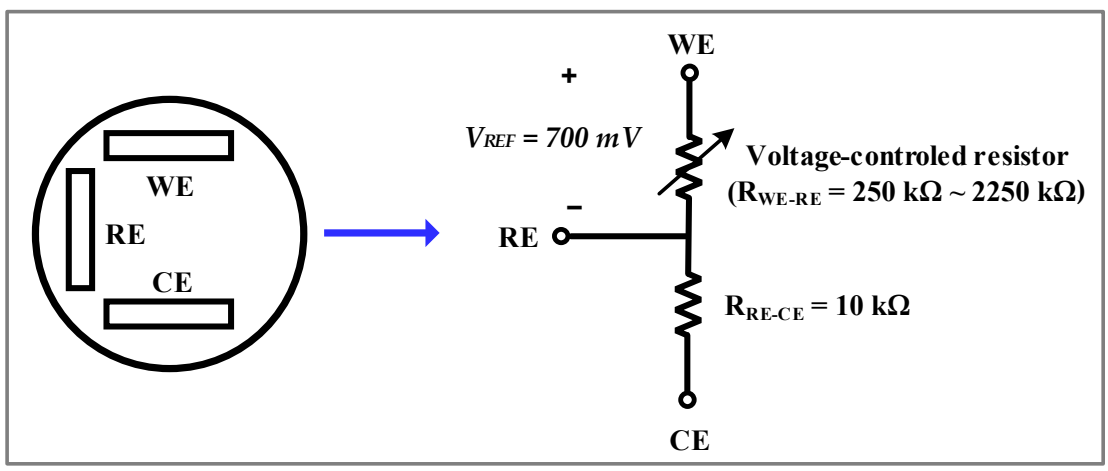

Figure 8. Configuration of the equivalent sensor model using a voltage-controlled resistor.

Figure 9 shows the layout of the circuit. The circuit was implemented using a 0.18 -um CMOS process with an active area of $1.073 \mathrm{~mm}^{2}$. The overall current consumption was $287.9 \mu \mathrm{W}$. 


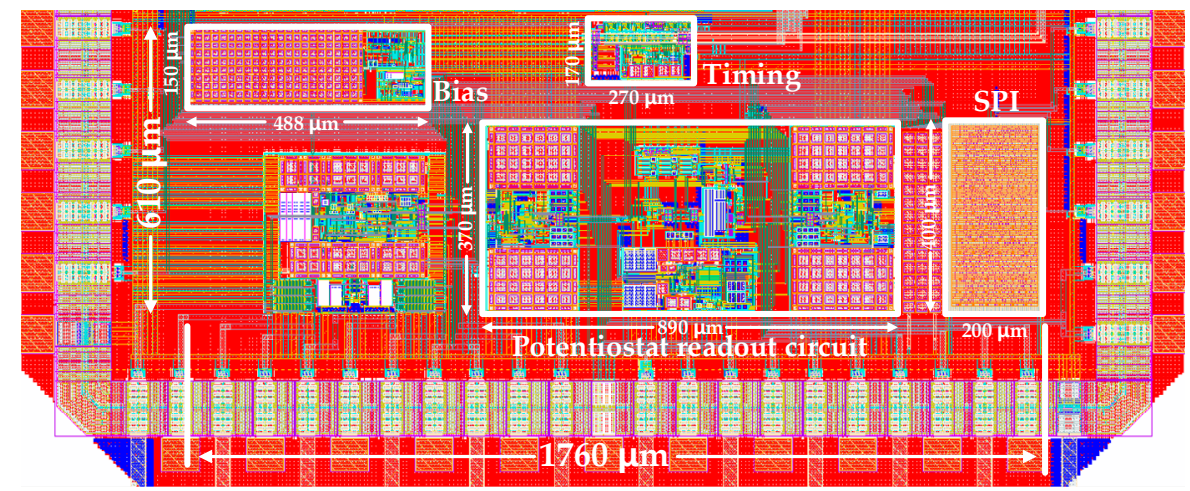

Figure 9. Layout of proposed readout circuit.

Figure 10a shows the input-output characteristics of the proposed current mirror between the input current $\left(I_{\text {SEN.IN }}\right)$ and output current $\left(I_{\text {SEN.OUT }}\right)$. The maximum error from 0 to $4.5 \mu \mathrm{A}$ for the input current is $1.129 \% \mathrm{FSO}$ (full scale output).

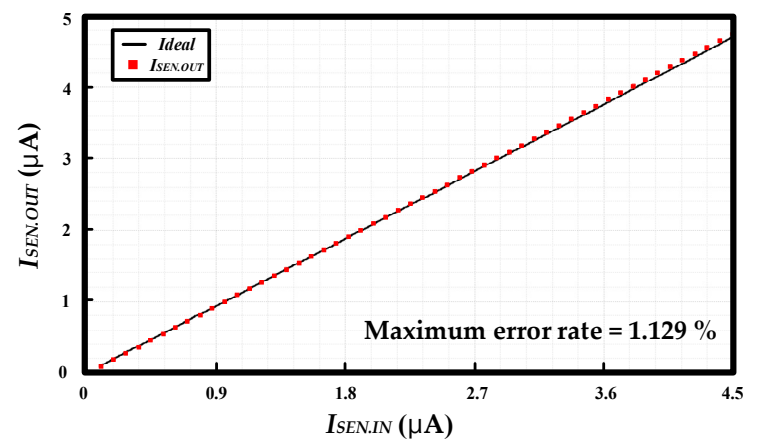

(a)

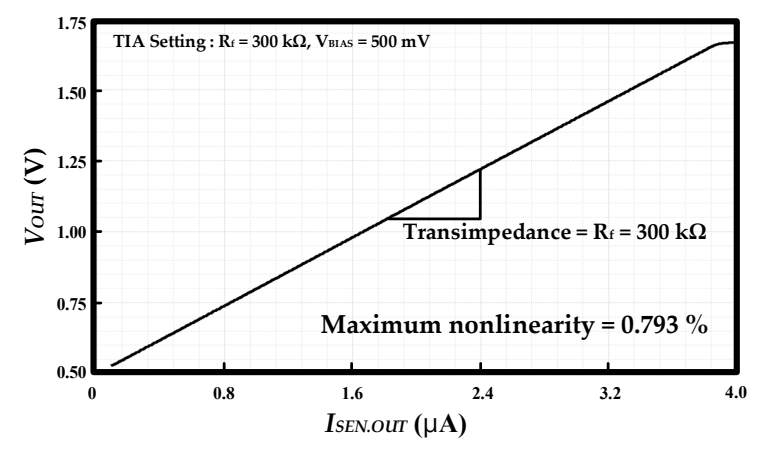

(b)

Figure 10. (a) Linearity simulation result of the sensing current; (b) linearity simulation result of the TIA.

Figure $10 \mathrm{~b}$ shows the transimpedance of the TIA was simulated to be $300 \mathrm{k} \Omega$ with a maximum nonlinearity of $0.793 \%$ in the current range of $3.83 \mu \mathrm{A}$.

Figure 11 shows the transient simulation results of the proposed potentiostat readout circuit. The resistance between the WE and RE varied from 250 to $2250 \mathrm{k} \Omega$, and the $V_{\text {BIAS }}$ was set to $500 \mathrm{mV}$. The transimpedance of the TIA was set to $300 \mathrm{k} \Omega$ and feedback capacitance of $10 \mathrm{pF}$. Because the output current is inversely proportional to the sinusoidal input resistance change of the electrochemical sensor, the red line $\left(I_{S E N}\right)$ and blue line $\left(V_{\text {OUT }}\right)$ have the waveform shapes of $1 /[1+\sin (\mathrm{x})]$.

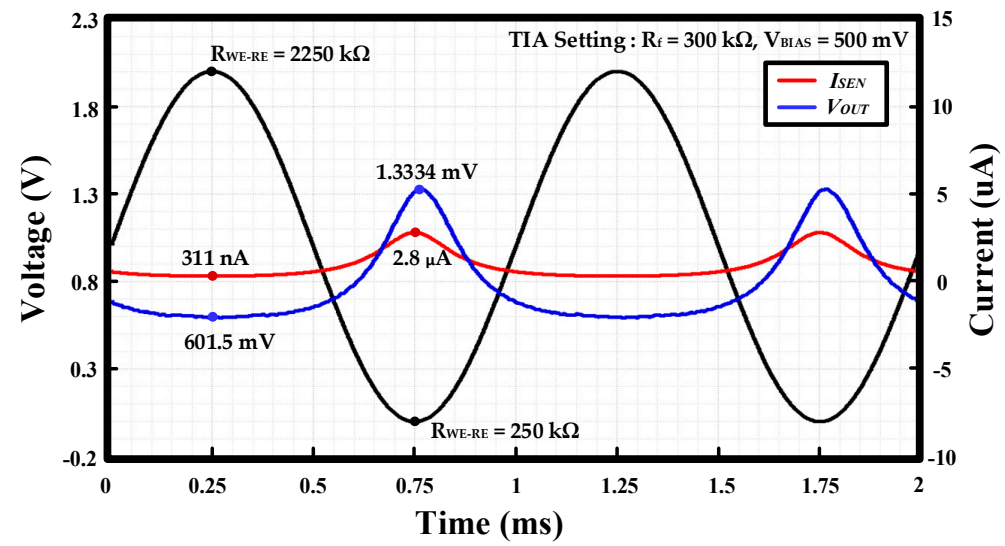

Figure 11. Output voltage simulation results of the current mirror and TIA. 
Figure 12 shows the stability simulation results of the TIA with the feedback transimpedance resistance of $300 \mathrm{k} \Omega$ and feedback capacitance of $10 \mathrm{pF}$. The open-loop gain (OLG) is $117 \mathrm{~dB}$, the unit gain bandwidth (UGBW) is $2.211 \mathrm{MHz}$, and the phase margin is $84.67 \mathrm{deg}$. This result shows stability at high-speed performance and can be setting the variable gain setup.
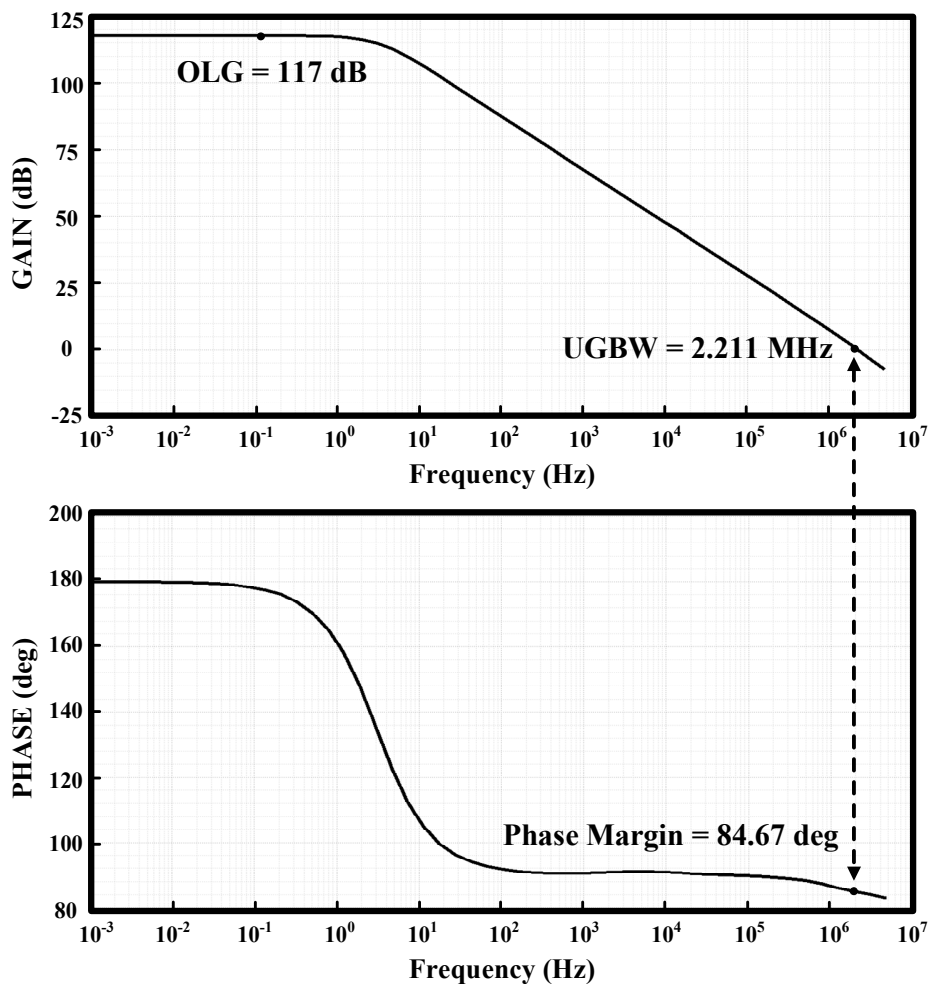

Figure 12. Stability simulation result of proposed TIA.

The input referred noise simulation results are shown in Figure 13. The input referred current noise at $1 \mathrm{~Hz}$ is reduced from $13.2775 \mathrm{pA} / \sqrt{ } \mathrm{Hz}$ to $936 \mathrm{fA} / \sqrt{ } \mathrm{Hz}$ by the chopper operation. The input-referred noise density and the integrated input-referred noise from $0.1 \mathrm{~Hz}$ to $1 \mathrm{kHz}$ are $21.7 \mathrm{pA}_{\mathrm{RMS}}$, respectively.

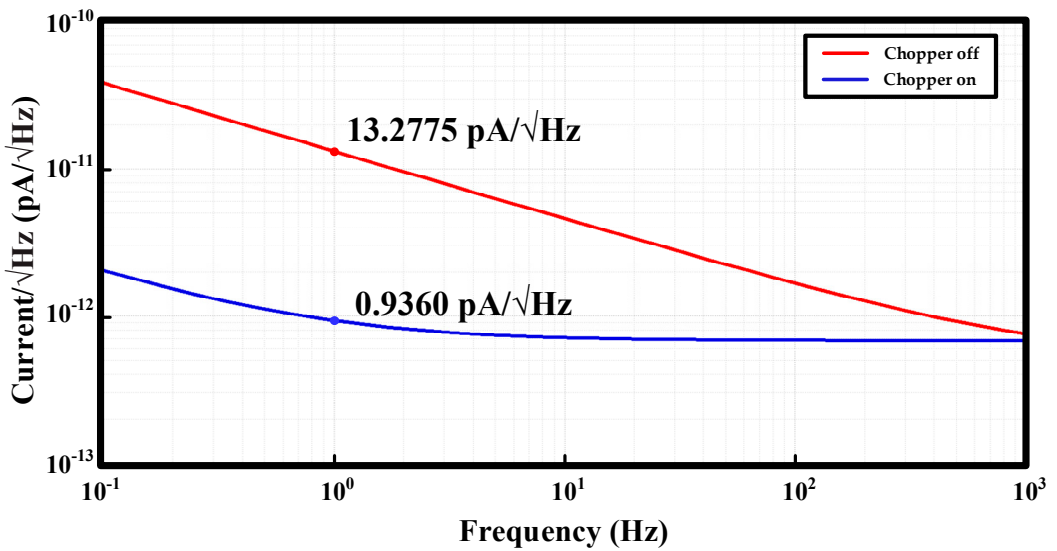

Figure 13. Input-referred noise simulation results of the readout circuit.

Table 1 shows noise contributors of readout circuit. When the chopper is disabled, the flicker noise components in the current mirror, $M_{1,2}$, form about $72 \%$ of the total noise. When the chopper is enabled, the main contributors are changed to the thermal noise of $M_{1,2}$. 
Table 1. Simulated noise contributors.

\begin{tabular}{cccc}
\hline Transistor & Noise Source & $\begin{array}{c}\text { Total Noise } \\
\text { Chopper Disable (\%) }\end{array}$ & $\begin{array}{c}\text { Total Noise } \\
\text { Chopper Enable (\%) }\end{array}$ \\
\hline $\boldsymbol{M}_{1,2}$ (current mirror) & Flicker & 71.52 & 12.44 \\
\hline $\boldsymbol{M}_{1,2}$ (current mirror) & Thermal & 8.03 & 31.02 \\
\hline $\boldsymbol{P} \boldsymbol{M}_{2,3}$ (TIA input pair) & Flicker & 4.06 & 1.40 \\
\hline $\mathbf{N} \mathbf{M}_{2,3}$ (TIA input pair) & Flicker & 3.62 & 1.38 \\
\hline $\mathbf{P M}_{4,5}$ (TIA cascode load) & Flicker & 3.53 & 0.18 \\
\hline $\mathbf{N} \mathbf{M}_{4,5}$ (TIA cascode load) & Flicker & 2.8 & 0.10 \\
\hline $\mathbf{N M}_{6,7}$ (TIA cascode) & Flicker & 0.18 & 2.78 \\
\hline
\end{tabular}

Figure 14 show the Monte-Carlo simulation results with $\mathrm{N}=200$. The input current, $V_{B I A S}$ and $R_{f}$, were fixed to $1 \mu \mathrm{A}, 500 \mathrm{mV}$, and $300 \mathrm{k} \Omega$, respectively. The desired nominal output of the TIA was $800 \mathrm{mV}$. In the simulation, the standard deviation of the TIA output was reduced from 2.49 to $0.12 \mathrm{mV}$ by the DEM operation in Figure 14d.

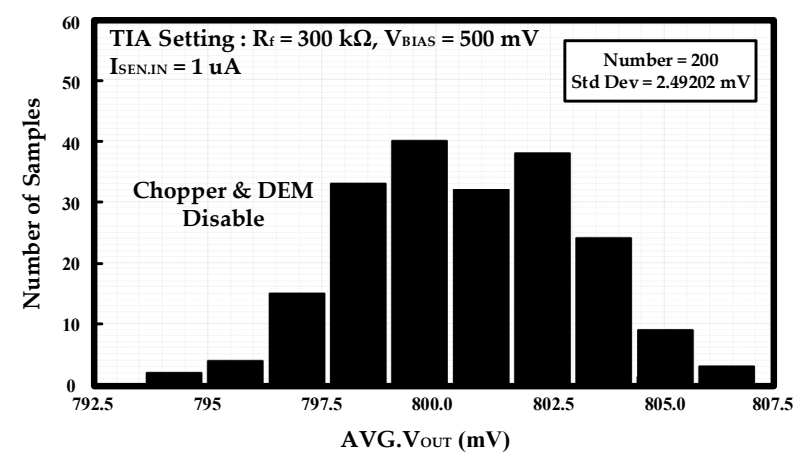

(a)

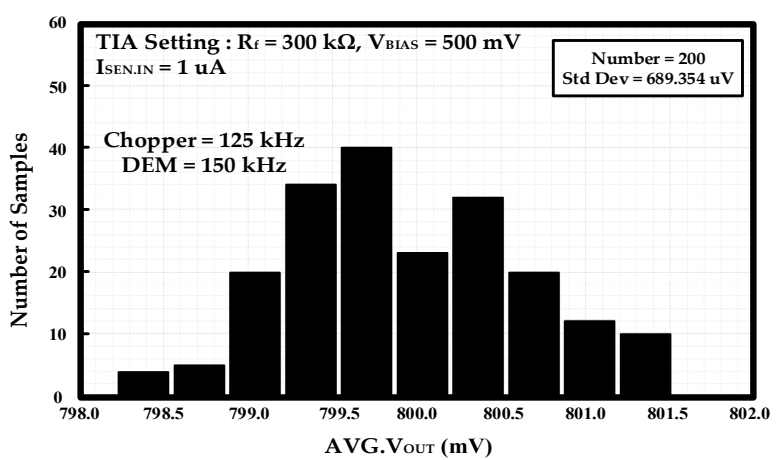

(c)

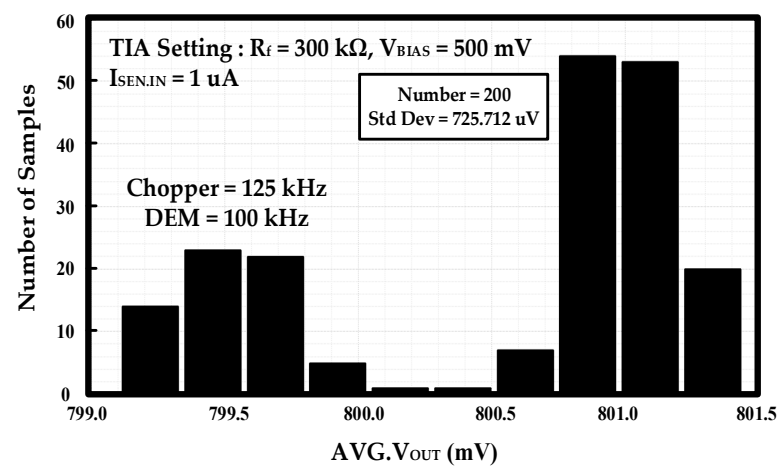

(b)

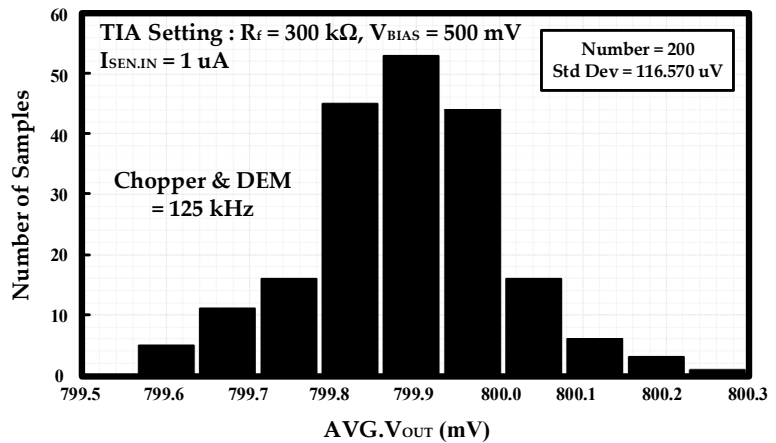

(d)

Figure 14. Mismatch simulation results when the chopper and DEM were (a) disabled; used different frequency $(\mathbf{b}) \mathrm{f}_{\mathrm{ch}}=125$ $\mathrm{kHz}, \mathrm{DEM}$ clock $=100 \mathrm{kHz} ;(\mathbf{c}) \mathrm{f}_{\mathrm{ch}}=125 \mathrm{kHz}, \mathrm{DEM}$ clock $=150 \mathrm{kHz}$; used same frequency $(\mathbf{d}) \mathrm{f}_{\mathrm{ch}}=$ DEM clock $=125 \mathrm{kHz}$.

As shown in Figure 14b,c, the standard deviation of the TIA output was 0.75 to $0.68 \mathrm{mV}$. The different chopper frequency and DEM frequency were used, and this may introduce performance degradation due to the IDM between the chopper and DEM frequencies. In Figure 14d, the same frequency for the chopper and the DEM is used, thus IMD between the chopper and DEM can be minimized.

Table 2 summarizes the performances of the proposed potentiostat readout circuit with those of previous studies $[4,16,17,22-24]$. The simulation results of this circuit achieve the wide input range, low noise, and mismatch-tolerant characteristics. 
Table 2. Performance summary comparison between the proposed potentiostat readout circuit and previous studies.

\begin{tabular}{|c|c|c|c|c|c|c|}
\hline & $\begin{array}{l}\text { This Work } \\
\text { (Simulated) }\end{array}$ & $\begin{array}{c}\text { TBCAS } \\
2013[22]\end{array}$ & $\begin{array}{l}\text { TCAS-I } \\
2009 \text { [4] }\end{array}$ & $\begin{array}{l}\text { Sensors } \\
2017[23]\end{array}$ & $\begin{array}{l}\text { IEEE Access } \\
2020[24]\end{array}$ & $\begin{array}{l}\text { ISCAS } 2012 \text { [16] } \\
\text { TCAS-I } 2013 \text { [17] }\end{array}$ \\
\hline $\operatorname{Process}(\mu \mathrm{m})$ & 0.18 & 0.35 & 0.18 & 0.18 & 0.065 & 0.13 \\
\hline Architecture & Current mirror & $\mathrm{CC}^{1}$ & Current mirror & FDDA $^{2}$ & $\begin{array}{l}\text { 1st-order } \\
\text { delta-sigma } \\
\text { converter }\end{array}$ & $\mathrm{CC}$ \\
\hline Chopper & $\mathrm{Y}(125 \mathrm{kHz})$ & $\mathrm{N}$ & $\mathrm{N}$ & $\mathrm{N}$ & $\mathrm{N}$ & $\mathrm{Y}(10 \mathrm{kHz})$ \\
\hline $\mathrm{DEM} O / \mathrm{X}$ & Y $(125 \mathrm{kHz})$ & $\mathrm{N}$ & $\mathrm{N}$ & $\mathrm{N}$ & $\mathrm{N}$ & Y $(500 \mathrm{~Hz})$ \\
\hline Output format & Voltage & Digital codes & Frequency & Voltage & Digital codes & Current \\
\hline Supply voltage (V) & 1.8 & 3.3 & 1.8 & 1.8 & 1.2 & 1.2 \\
\hline Power consumption $(\mu \mathrm{W})$ & 287.9 & 188 & 50 & 53 & $\begin{array}{c}15-25 \\
(0.1-1.5 \mu \mathrm{A}) \\
\end{array}$ & 4 \\
\hline Input current range (A) & $100 \mathrm{n}-3.83 \mu$ & $24 \mathrm{p}-350 \mathrm{n}$ & $1 \mathrm{n}-1 \mu$ & $100 \mathrm{u}-840 \mathrm{u}$ & $100 \mathrm{n}-1.5 \mu$ & $8.6 p-350 n$ \\
\hline $\begin{array}{l}\text { Input-referred noise } \\
\qquad\left(\mathrm{pA}_{\mathrm{RMS}}\right)\end{array}$ & $\begin{array}{c}21.7 \\
(0.1 \mathrm{~Hz} \sim 1 \mathrm{kHz}) \\
\text { (simulated) }\end{array}$ & $\begin{array}{c}24 \\
(100 \mathrm{~Hz} \mathrm{BW}) \\
\text { (measured) }\end{array}$ & $\mathrm{N} / \mathrm{A}$ & $\mathrm{N} / \mathrm{A}$ & $\begin{array}{c}168.3^{3} \\
(1 \mathrm{~Hz} \text { BW) } \\
\text { (measured) }\end{array}$ & $\begin{array}{c}20.31^{4} \\
(0.01 \mathrm{~Hz} \\
\sim 1 \mathrm{kHz}) \\
\text { (measured) }\end{array}$ \\
\hline
\end{tabular}

${ }^{1}$ Current conveyer; ${ }^{2}$ Fully differential difference amplifier; ${ }^{3}$ Output digital code is limited to 10 bits; $^{4}$ Standard deviation $(1 \sigma)$ of output current with $100 \mathrm{pA}$ input current.

\section{Conclusions}

This paper proposes a potentiostat readout circuit with a low-noise and mismatchtolerant current mirror using chopper stabilization and dynamic element matching (DEM) for electrochemical sensors. The potentiostat electrochemical current-mode sensors convert potential differences into current signals according to the concentration of the solution, and the readout circuit converts current signals into voltage signals.

The proposed potentiostat readout circuit consists of a potentiostat biasing stage using $\mathrm{CA}$, a gain-boosted cascode current mirror, TIA, I/V reference, SPI, oscillator, and a timing generator. In order to detect small changes in current, the proposed readout circuit with mismatch-tolerant and low-noise characteristics is essential. For this purpose, a chopper was adopted for the input and output stages of the CA, current mirror, and TIA. The DEM technique was applied to make it mismatch-tolerant. Thus, the clock generator for chopping, along with the DEM and an SPI for communication to the digital circuits, were integrated into a single chip.

The proposed readout circuit was under fabricate by implementing a $0.18-\mu \mathrm{m}$ CMOS process with an active area of $1.073 \mathrm{~mm}^{2}$. It consumed $287.9 \mu \mathrm{W}$ of power at a $1.8 \mathrm{~V}$ supply voltage. The input-referred current noise was reduced to $936 \mathrm{fA} / \sqrt{ } \mathrm{Hz}$ at $1 \mathrm{~Hz}$, and the input-referred noise from $0.1 \mathrm{~Hz}$ to $1 \mathrm{kHz}$ was $21.7 \mathrm{pA}_{\mathrm{RMS}}$. The input current range was in the range of $100 \mathrm{nA}$ to $3.83 \mu \mathrm{A}$ (maximum nonlinearity $<1 \%$ ). The standard deviation of the TIA output was reduced from $2.49 \mathrm{mV}$ to $0.12 \mathrm{mV}$ by the DEM operation. These results suggest that the readout circuit proposed in this paper is suitable as an electrochemical sensor using a potentiostat.

Author Contributions: Conceptualization, K.N. and H.K. (Hyoungho Ko); methodology, H.K. (Hyoungho Ko); software, K.N.; validation, K.N., G.C. and H.K. (Hyungseup Kim); formal analysis, G.C.; investigation, M.Y.; resources, H.K. (Hyungseup Kim); data curation, K.N.; writing—original draft preparation, K.N.; writing—-review and editing, H.K. (Hyoungho Ko); visualization, K.N.; supervision, H.K. (Hyungseup Kim); project administration, H.K. (Hyoungho Ko); funding acquisition, H.K. (Hyoungho Ko). All authors have read and agreed to the published version of the manuscript.

Funding: This research was supported by the MSIT (Ministry of Science and ICT), Korea, under the ITRC (Information Technology Research Center) support program (IITP-2021-2017-0-01635) supervised by the IITP (Institute for Information \& Communications Technology Planning \& Evaluation).

Institutional Review Board Statement: Not applicable. 
Informed Consent Statement: Not applicable.

Data Availability Statement: Not applicable.

Acknowledgments: The EDA tool was supported by the IC Design Education Center (IDEC), Korea.

Conflicts of Interest: The authors declare no conflict of interest.

\section{References}

1. Kim, J.; Ko, H. A $1.2 \mathrm{~V}$ low-power CMOS chopper-stabilized analog front-end IC for glucose monitoring. IEEE Sens. J. 2015, 16, 6517-6518. [CrossRef]

2. Zuo, L.; Islam, S.K.; Mahbub, I.; Quaiyum, F. A low-power 1-V potentiostat for glucose sensors. IEEE Trans. Circuits Syst. II Express Briefs 2015, 62, 204-208. [CrossRef]

3. Kwon, J.; Lee, Y.; Lee, T.; Ahn, J. Aptamer-based field-effect transistor for detection of avian influenza virus in chicken serum. Anal. Chem. 2020, 92, 5524-5531. [CrossRef] [PubMed]

4. Ahmadi, M.M.; Jjulien, G.A. Current-mirror-based potentiostats for three-electrode amperometric electrochemical sensors. IEEE Trans. Circuits Syst. I Regul. Pap. 2009, 56, 1339-1348. [CrossRef]

5. Chung, W.; Paglinawan, A.C.; Kuo, T. A $600 \mu \mathrm{W}$ readout circuit with potentiostat for amperometric chemical sensors and glucose meter applications. In Proceedings of the 2007 IEEE Conference on Electron Devices and Solid-State Circuits, Tainan, Taiwan, 20-22 December 2007. [CrossRef]

6. Ahmadi, M.M.; Jullien, G.A. A very low power CMOS potentiostat for bioimplantable applications. In Proceedings of the Fifth International Workshop on System-on-Chip for Real-Time Application (IWSOC'05), Banff, AB, Canada, 20-24 July 2005; pp. 184-189. [CrossRef]

7. Bouhoun, M.L.; Blondeau, P.; Louafi, Y.; Andrade, F.J. A Paper-Based Potentiometric Platform for Determination of Water Hardness. Chemosensors 2021, 9, 96. [CrossRef]

8. Wang, W.-S.; Kuo, W.-T.; Huang, H.-Y.; Luo, C.-H. Wide dynamic range CMOS potentiostat for amperometric chemical sensor. Sensors 2010, 10, 1782-1797. [CrossRef] [PubMed]

9. Matzeu, G.; Florea, L.; Diamond, D. Advances in wearable chemical sensor design for monitoring biological fluids. Sens. Actuators B Chem. 2015, 211, 403-418. [CrossRef]

10. Lefrou, C.; Fabry, P.; Poignet, J.C. Electrochemistry; Springer: Berlin, Germany, 2009; pp. 68-90.

11. Mohanty, S.P.; Konugianos, E. Biosensors: A tutorial review. IEEE Potentials 2006, 25, 35-40. [CrossRef]

12. Fischer, S.; Muratore, D.; Weinreich, S.; Peres, A.P.; Walker, R.M.; Gupta, C.; Howe, R.T.; Murmann, B. Low-noise integrated potentiostat for affinity-free protein detection with $12 \mathrm{nV} / \mathrm{rt}-\mathrm{Hz}$ at $30 \mathrm{~Hz}$ and $1.8 \mathrm{pA}^{\mathrm{rms}}$ Resolution. IEEE Solid-State Circuits Lett. 2019, 6, 41-44. [CrossRef]

13. Martin, S.M.; Gebara, F.H.; Strong, T.D.; Brown, R.B. A fully differential potentiostat. IEEE Sens. J. 2009, 9, 135-142. [CrossRef]

14. Ayers, S.; Gillis, K.D.; Lindau, M.; Minch, B.A. Design of a CMOS potentiostat circuit for electrochemical detector arrays. IEEE Trans. Circuits Syst. I Regul. Pap. 2007, 54, 736-744. [CrossRef] [PubMed]

15. Turner, R.F.B.; Harrison, D.J.; Baltes, H.P. A CMOS potentiostat for amperometric chemical sensors. IEEE J. Solid-State Circuits 1987, 22, 473-478. [CrossRef]

16. Jafari, H.M.; Genov, R. Bidirectional current conveyer with chopper stabilization and dynamic element matching. In Proceedings of the 2021 IEEE International Symposium on Circuits and Systems (ISCAS), Seoul, Korea, 20-23 May 2012; pp. 1079-1082. [CrossRef]

17. Jafari, H.M.; Genov, R. Chopper-stabilized bidirectional current acquisition circuits for electrochemical amperometric biosensors. IEEE Trans. Circuits Syst. I: Regul. Pap. 2013, 60, 1149-1157. [CrossRef]

18. Rooijers, T.; Karmakar, S.; Kusuda, Y.; Huijsing, J.H.; Makinwa, K.A.A. 31.4 A Chopper-Stabilized Amplifier with-107dB IMD and $28 \mathrm{~dB}$ Suppression of Chopper-Induced IMD. In Proceedings of the 2021 IEEE International Solid-State Circuits Conference (ISSCC), San Fransisco, CA, USA, 13-22 February 2021; pp. 440-480. [CrossRef]

19. Busoni, L.; Carla, M.; Lanzi, L. A comparison between potentiostatic circuits with grounded work or auxiliary electrode. Rev. Sci. Instrum. 2002, 73, 1921. [CrossRef]

20. Fidler, J.C.; Penrose, W.R.; Bovis, J.P. A potentiostat based on a voltage-controlled current source for use with amperometric gas sensors. IEEE Trans. Instrum. Meas. 1992, 41, 308-310. [CrossRef]

21. Anoop, A.E.; Mohan, N.M.; Guruvayurappan, K. Simulation of a multi-strip blood glucometer. In Proceedings of the TENCON 2014-2014 IEEE Rehion 10 Conference, Bankok, Thailand, 22-25 October 2014; pp. 1-4. [CrossRef]

22. Nazari, M.H.; Mazhab-Jafari, H.; Leng, L.; Guenther, A.; Genov, R. CMOS neurotransmitter microarray: 96-channel integrated potentiostat with on-die microsensors. IEEE Trans. Biomed. Circuits Syst. 2013, 7, 338-348. [CrossRef] [PubMed]

23. Ghodsevali, E.; Morneau-Gamache, S.; Mathault, J.; Landari, H.; Boisselier, É.; Boukadoum, M.; Gosselin, B.; Miled, A. Miniaturized FDDA and CMOS based potentiostat for bio-applications. Sensors 2017, 17, 810. [CrossRef] [PubMed]

24. Aymerich, J.; Marquez, A.; Munoz-Berbel, X.; Javier Del Campo, F.; Guirado, G.; Teres, L.; Serra-Graells, F.; Dei, M. A 15- $\mu$ W 105-dB 1.8-Vpp potentiostatic delta-sigma modulator for wearable electrochemical transducers in 65-nm CMOS technology. IEEE Access 2020, 8, 62127-62136. [CrossRef] 